\title{
Running down observatories
}

SIR - As a university astronomer who has had much to do with both the Science and Engineering Council (SERC) observatories at all levels, including serving on committees charged with looking into whether they could best be merged with each other, or elsewhere, I would like to comment on your leading article on "Running telescopes"' (Nature 9 May, p.86) which is a mine of misinformation.

Before there is any talk of closing or merging anything, with all the personal and professional upset and delay that will certainly entail, the case has to be made, and indisputably made, that there are significant inefficiencies in the present system of two observatories at Herstmonceux and Edinburgh, sharing some of their tasks, computing for example, with the Rutherford Appleton Laboratory. To that extent I agree with Nature that the widest terms of reference must be given to the new committee, if there has to be one so shortly after the last, which I doubt, looking into the best way of running our overseas telescopes.

Building and operating a high technology instrument on an exceedingly remote and sometimes physically hostile foreign site, transporting shifts of UK university astronomers there, looking after them, educating them in the intricacies of the local equipment, which has to be maintained at the highest efficiency, providing them with the technical help to get first rate data, and later the sophisticated computer network required to reduce such data, must be a technical and management challenge of the same order as running an aircraft carrier full of Harriers at war in the Falklands. Mistakes are inevitable, and any number of committees can be set up to look into how the task can be better done, and of course the less they know about the practicalities the easier it will be for them to recommend sweeping changes.

The professional and the user, however, will only be convinced by a proper comparison, carried out largely by observationalists, of the existing UK set-up with its competent counterparts abroad such as the Cerro Tololo Inter-American Observatory (US) and the European Southern Observatory based in Munich. My own survey, for what it was worth, showed the UK observatories in a very favourable light. If the new committee fails to make a similar but much more careful comparison, coopting the advice of astronomers abroad, and taking the time to do it properly, they will certainly have failed astronomers, like myself, out in the UK universities. At present we are lucky enough to have access to shared facilities which are remarkable not for their size, as your leading article implies, but for their sheer quality, something in which both observatories, and the Rutherford Appleton Laboratory, can take a just pride. Such quality arises not from lavish expenditure but from vision, high skill and dedication, as well as the very closest cooperation with the user community.

All this could be easily lost in the sort of reorganization or tidying up so beloved by (and alas in the United Kingdom indulged in by) second-rate administrators on their way up the civil service career ladder. One would have thought the amalgamations that led to British Leyland would have taught somebody up there a lesson.

The predictions are that the United States will be running short of astronomers in 2-3 years time. The demoralization that is now spreading through our UK observatories as a result of continual misinformed sniping by those who do not use them, and a neverending series of superficial reviews, can in the end have only one result. And when the best SERC people have left on the plane, the rest of us, contemplating the resulting inevitable decline in the competitiveness of our own far from ambitious facilities (our colleagues abroad are going up to 10 or 15 metre class telescopes), will be studying the job columns too. To their credit, our observatories have played a major part recently in catapulting British optical and infrared astronomy from mediocrity into the front rank. In a society increasingly settling for the seedy and the second-rate perhaps that is their crime.

MiChaEl DISNEY

Department of Applied Mathematics

and Astronomy,

University College,

PO Box 78,

Cardiff CFI IXL, UK

\section{Philistinism?}

SIR - If the idea of exploring more unorthodox ways of funding science than using the increasingly tired arguments for an ever-increasing Science Vote is the role of a scientific philistine then I must accept that label. What a pity though that a once great industrial society should display cultural antipathy to modern commerce of the sort revealed in your leading article (25 April, p.657).

My purpose in trying to provoke a debate on these important issues (not incidentally the unwitting act on my part that you seem to think) is to get scientists to consider a little more, in these financially difficult times, their role in society and their justification for that role being supported from the country's tax base. How you can contend that it is valid to challenge the scientific community with such arguments but not ask individual scientists to accept their implications is beyond me.

Of course I realize that not all science is commercially exploitable. Much of my own research on viruses has been in that category. But I still claim that there is a need for scientists to think purposefully about whether commercial opportunity ex- ists and how it can be harnessed. Though there are some of us who need no such urging, this is not an area in which we have demonstrated much skill in the past. We might all benefit if more of us thought it important and generated income for ourselves, our institutions and our country as a result.

A major point in my Times letter that you did not choose even to misquote was that such a strategy could well generate funds for basic science both directly and from government. It is surely worth giving our thinking a nudge in this direction, to counterbalance the traditional arguments so frequently put, even at the risk of incurring the wrath of the Editor of Nature.

K.A. HARraP

Wolfson College, Oxford OX2 6UD, UK

\section{Imunovir}

SIR - Helen Wright's reply ${ }^{1}$ fails to destroy Dimitri Viza's complaint ${ }^{2}$ that the drug isoprinosine was hyped by excessive promotion, but rather confirms his implicit contention that the publicity for a product is proportional to the doubts about its activity. This contrasts with the case of an effective treatment for herpes; there has been no excessive publicity in the promotions of acyclovir, a drug whose virtues and limitations are well documented.

All but one of the references cited by Wright to prove the efficacy of Imunovir are to communications at meetings between 1973 and 1981, suggesting that none was followed up by a formal paper. She omits references to work suggesting the absence of effect ${ }^{3,4}$

There is a striking difference between Wright's arguments in defence of Imunovir - a 60 per cent cure of herpes bouts within a week, the praise of Prix Galien's jury for a drug arousing "'new hopes for the treatment of infectious diseases, auto-immune diseases, allergy and - why not? cancer" and the absence as yet of any convincing clinical trial. This is even more baffling if one considers that isoprinosine has been tested for more than 12 years.

I cannot therefore but agree that pharmaceutical companies would be well advised to avoid raising excessive hopes through lay media or otherwise. Since mediaeval times, people have been wary of panaceas. This is only one of the reasons why I am prepared to wager that in another five years isoprinosine will have fallen into oblivion. But Viza's proposal that there should be more scrutiny and responsibility in lay publications deserves to succeed.

JEAN-YVES FOLLEZOU

Centre des Tumeurs,

Hôpital de la Pitié,

75013 Paris, France

I. Wright, H.J. Nature 314, 126 (1985).

Viza, D. Nature 313, 344 (1985)

3. Kalimo, K.O.K., Joronen, I.A. \& Havu, V.K. Archs Derm. 119,463 (1983).

4. Glasgow, L.A. \& Galasso, G.J. J.infect.Dis. 126, 162 (1972) 